\title{
Endorotor-based endoscopic necrosectomy avoiding the superior mesenteric artery
}

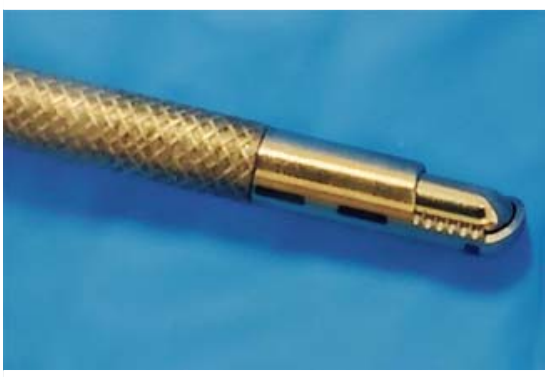

- Fig. 1 The catheter tip emerging from a therapeutic endoscope. The fixed outer cannula and the hollow inner cannula can be seen.

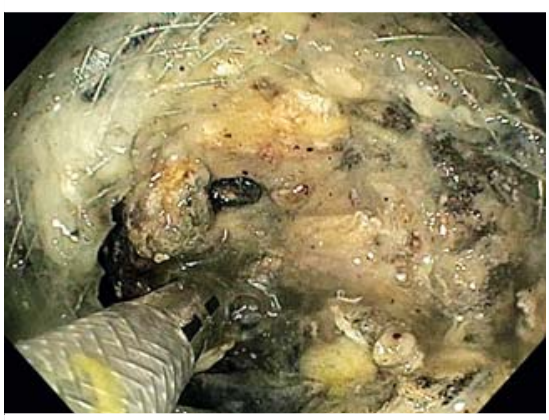

$\checkmark$ Fig. 2 The catheter inside the endoscope passing through a previously placed Axios stent (Boston Scientific, Marlborough, Massachusetts, USA) to start direct endoscopic necrosectomy.

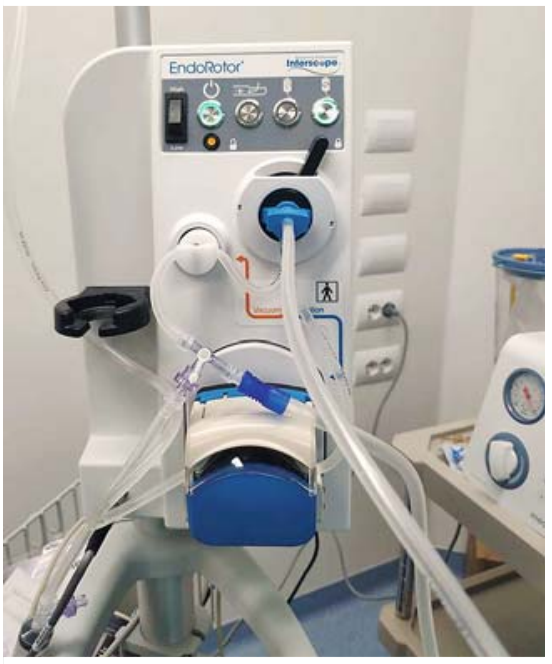

Fig. 3 Endorotor system console (Interscope, Inc., Whitinsville, Massachusetts, USA). Connections to the catheter and vacuum system can be seen.

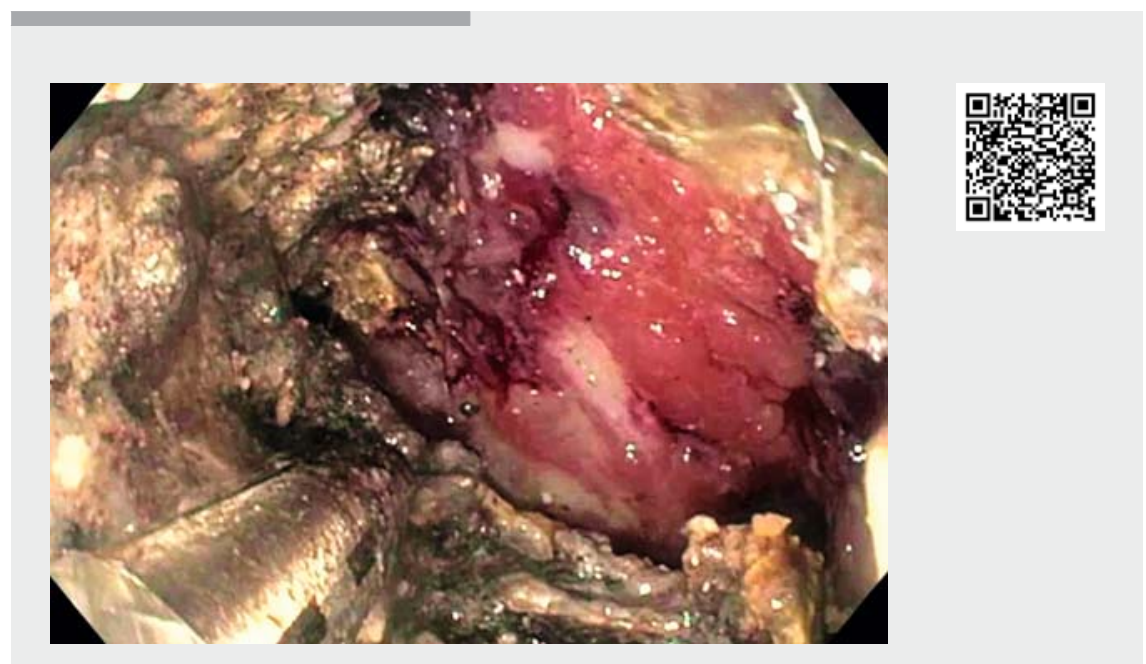

$\checkmark$ Video 1 Endoscopic necrosectomy with Endorotor (Interscope, Inc., Whitinsville, Massachusetts, USA), avoiding the superior mesenteric artery.

A 67 -year-old man with a $15-\mathrm{cm}$ pancreatic necrotic collection was transferred to our unit after 2 months' hospitalization for necrotizing pancreatitis. His conditions was poor, with decreased mental status, high fever, neutrophilic leukocytosis (white blood cells $27.6 \times 10^{9} / \mathrm{L}$, neutrophils $93.1 \%$ ), and signs of sepsis (C-reactive protein $150.5 \mathrm{mg} / \mathrm{L}$, procalcitonin $9.83 \mathrm{ng} / \mathrm{mL})$.

Emergency endosonography-guided drainage using a $15 \times 10 \mathrm{~mm}$ Axios stent (Boston Scientific, Marlborough, Massachusetts, USA) mounted onto a cautery device was successfully performed. During the procedure a major vessel was observed inside the collection. He was sent for embolization but angio-computed tomography revealed the vessel to be the superior mesenteric artery (SMA) and embolization prior to direct endoscopic necrosectomy (DEN) was aborted. A decision to pursue DEN was made and the Endorotor system (Interscope, Inc., Whitinsville, Massachusetts, USA) ( $\mathbf{F i g . 1}$ ), which allows constant endoscopic visualization during necrosectomy ( $\triangleright$ Fig.2), was utilized. The procedure was performed using a dedicated Endorotor XT catheter, high rotating speed (1700 rpm), and progressive increase of suction up to $60 \mathrm{~L} / \mathrm{min}$ ( $\triangleright$ Fig.3), with careful visualization of the site at which the catheter was active ( $\bullet$ Video 1 ).

After two DEN sessions (40 and 120 minutes' duration, respectively), without any complications, only minimal debris remained in the area proximal to the SMA. A double-pigtail stent was placed through the Axios stent and the patient was discharged home.

At 3 weeks' follow-up, both stents were removed, and the patient remained in good clinical condition thereafter.

Endorotor is a new endoscopic rotating morcellator device, which reported successful accomplishment of DEN in two patients in whom conventional necrosectomy failed [1], and in another patient [2] with a collection containing $70 \%$ necrotic content. In our case, the Endorotor catheter performed DEN under constant endoscopic visualization, allowing successful treatment despite the presence of the SMA inside the collection.

Endoscopy_UCTN_Code_TTT_1AR_2AI 


\section{Competing interests}

Dr. Larghi has received fees for lecture and training from Pentax Medical and Boston Scientific. He has also received research grant from Medtronic.

Prof. Costamagna is a consultant for Olympus Medical, Boston Scientific Corp., Cook Medical.

The authors

Gianenrico Rizzatti ${ }^{1,2}$, Mihai Rimbaș ${ }^{3}$, Mariella De Riso ${ }^{4}$, Michele Impagnatiello ${ }^{5}$, Guido Costamagna ${ }^{1,2}$, Alberto Larghi ${ }^{1,2}$

1 Digestive Endoscopy Unit, Fondazione Policlinico Universitario A. Gemelli IRCCS Università Cattolica del Sacro Cuore, Rome, Italy

2 Center for Endoscopic Research Therapeutics and Training, Catholic University, Rome, Italy

3 Gastroenterology and Internal Medicine Departments, Colentina Clinical Hospital, Carol Davila University of Medicine, Bucharest, Romania

4 Department of Anesthesiology, Fondazione Policlinico Universitario A. Gemelli IRCCS -
Università Cattolica del Sacro Cuore, Rome, Italy

5 Internal Medicine, Gastroenterology and Hepatology, Fondazione Policlinico Universitario A. Gemelli IRCCS, Rome, Italy

\section{Corresponding author}

\section{Alberto Larghi, MD, PhD}

Digestive Endoscopy Unit, Fondazione Policlinico Universitario A. Gemelli IRCCS Università Cattolica del Sacro Cuore, Largo A. Gemelli 8, 00168, Rome, Italy Fax: +39-06-30156581

alberto.larghi@policlinicogemelli.it

\section{References}

[1] van der Wiel SE, Poley JW, Grubben MJAL et al. The EndoRotor, a novel tool for the endoscopic management of pancreatic necrosis. Endoscopy 2018; 50: E240-E241

[2] Bazarbashi AN, Ge PS, de Moura DTH et al. A novel endoscopic morcellator device to facilitate direct necrosectomy of solid walled-off necrosis. Endoscopy 2019; 51: E396E397
Bibliography

Endoscopy 2020; 52: E420-E421

DOI 10.1055/a-1151-4694

ISSN 0013-726X

published online 24.4.2020

(c) 2020. Thieme. All rights reserved.

Georg Thieme Verlag KG, Rüdigerstraße 14 ,

70469 Stuttgart, Germany

\section{ENDOSCOPY E-VIDEOS}

https://eref.thieme.de/e-videos

Endoscopy E-Videos is a free access online section, reporting 回: on interesting cases and new techniques in gastroenterological endoscopy. All papers include a high quality video and all contributions are freely accessible online.

This section has its own submission website at

https://mc.manuscriptcentral.com/e-videos 